\title{
Changing Patterns of Perceived ICT Skill Levels of Elderly Learners in a Digital Literacy Training Course
}

\author{
Makiko Miwa, Emi Nishina, Masaaki Kurosu, Hideaki Takahashi, \\ Yoshitomo Yaginuma, Yoko Hirose, Toshio Akimitsu \\ Faculty of Liberal Arts \\ The Open University of Japan \\ miwamaki@ouj.ac.jp
}

\begin{abstract}
Background. In 2010, the Open University of Japan began offering a onesemester face-to-face digital literacy (DL) training course at each of its 50 study centers to help elderly students use personal computers (PC) and the Internet for study. A series of checklists was completed by students before and after each DL training course to assess their achievement.

Objectives. This study identified the degree to which students' perceived information and communication technology (ICT) skills had changed one to three years after completion of the DL training course. It revealed which skills were retained and which skills declined.

Methods. A survey questionnaire was sent to 2,112 students who took the DL training course and we received 1,153 responses. Questions focused on students' daily use of a PC and the Internet, and opportunities to learn DL skills after the training course. The same items were used in a checklist to assess ICT skills, and the two sets of data were compared to identify the level of retention of 18 ICT skills.

Results. Overall, scores for 16 of the 18 ICT skills declined. It was found that students who used a PC and the Internet more frequently and those who continued learning by self-instruction or peer learning in the community retained their ICT skills.

Contributions. Visualization of changing patterns in ICT skills helped identify insufficient elements of the DL training course. This information is useful in refining course content and in planning post-course support for DL training attendees.
\end{abstract}

\section{INTRODUCTION}

The Open University of Japan (OUJ) offers distance-learning programs through courses broadcast on TV and radio, in addition to face-to-face courses at its 50 study centers nationwide. In 2015, OUJ also began offering online courses. Although OUJ has implemented information and communication technology (ICT), including Web-based delivery of courses, online registration, and digital library services, these have not been fully utilized by students. This is mainly because a considerable proportion of older students at OUJ have no formal training and little experience in using personal computers (PCs) and/or the Internet. To prepare these students to take online courses and to maximize Web-based learning opportunities, in 2010, OUJ began offering a two-day intensive digital literacy (DL) training 
course every semester in classrooms with networked PCs at its study centers using originally developed standardized teaching materials and a common syllabus (Miwa et al., 2013).

This paper reports the results of a survey that identified the degree to which students' perceived level of DL skills and self-efficacy changed one to three years following the completion of the DL training course, and which ICT skills were retained or declined. Our objective was to gather information that would be useful to refine DL course content and plan post-course support for students. We were also interested in investigating whether the retention of ICT skills, as perceived by the students, and self-efficacy were related to the students' age.

\section{LITERATURE REVIEW}

The term "digital divide" refers to the fundamental gap between those who have access to computers, the Internet, and online information and those who do not. Studies have reported age as one of the significant sources of the digital divide in addition to gender, salary, education, and professional practices (OECD, 2005). Schäffer (2007) suggested that generation-specific media use reflects what people learned during their adolescence and with the media available at that time. Other studies identified cognitive abilities, computer selfefficacy, and computer anxiety as mediators of age and the digital divide (Czaja et al., 2006). However, nowadays, access to information resources on the Internet is necessary for older people even after retirement. For example, older students who are studying in e-learning environments are expected to use digital libraries, Internet search engines, word processing software, spreadsheets, and presentation software at the same level as younger students.

Several studies have reported the effects and retention of DL training for elderly people. Naumanen and Tukiainen (2010) suggested that the learning program for the elderly be strongly facilitated by peer support as well as having a jointly planned content that is tailored to the needs, motivation, and ability of learners. In the USA, Echt, Morell and Park (1998) compared the retention of computer skills of two age groups (60-74 years versus 7589 years) between two types of computer skill training methods (animated multimedia CDROM versus printed manual). The younger age group made fewer errors in a test of their computer skills performance, while the older group tended to have forgotten information they learned during the training sessions; however, there was no difference between the different training methods. Wong, Chen, Lee, Fung and Law (2014) compared differences in changes of perceived self-efficacy during basic-level computer training in Hong Kong using a pre- and post-survey method and noted that beginners' perceived self-efficacy tended to improve, while additional training for those who already had a certain level of ICT skills did not lead to improvement. These findings indicate that retention of ICT skills is negatively associated with the age of the learner. Thus, existing studies imply the need for special consideration of older students in improving their ICT skills.

\section{PURPOSE OF THE STUDY}

We aimed to identify whether students' perceived level of ICT skills acquired in the DL training course was retained after one to three years. We also examined how these skills were utilized after they completed the course. Specifically, we traced changes in self-assessed ICT skills by comparing ICT skills reported in the checklist filled before (pretest) and after (posttest) the DL training course, as well as with a survey conducted one to three years later.

We developed four research hypotheses to guide the study. The perceived level of ICT skills acquired through the DL training course remained unchanged after one to three years. 
Table 1. Changes in Scores in Student ICT Skills

\begin{tabular}{|c|c|c|c|c|c|c|c|c|c|c|}
\hline \multirow[t]{2}{*}{ ICT Skill (Learning Outcome) } & \multirow[t]{2}{*}{$\mathbf{v}^{1}$} & \multicolumn{2}{|c|}{ Pretest } & \multirow[t]{2}{*}{01} & & \multicolumn{2}{|c|}{ Posttest } & & \multicolumn{2}{|c|}{ Survey } \\
\hline & & $M$ & & & & $M$ & Ie & & $M$ & Me \\
\hline & & 2.79 & 3 & * & 32 & 4 & 4 & * & 3.86 & 4 \\
\hline using & 1,118 & 3.40 & 4 & k* & 1,114 & 4.19 & 4 & * & 4.35 & 5 \\
\hline l. & 1,054 & & 3 & & 1,067 & 3.83 & 4 & $.014^{*}$ & 3.7 & 4 \\
\hline & 00 & 2 & 3 & $* *$ & 1,098 & 4.13 & 4 & $.046^{*}$ & 4.07 & 4 \\
\hline & ) & 2. & 3 & .0 & 1 & 3 & 4 & 2* & 3.7 & 4 \\
\hline f. $\mathrm{Ab}$ & 2 & 1. & 1 & ** & 1,077 & 3 & 4 & & 2.87 & 3 \\
\hline g. $\mathrm{Ab}$ & 093 & & 1 & & 1,093 & 3.83 & 4 & & 3.24 & 4 \\
\hline $\begin{array}{l}\text { 1. A } \\
\text { In }\end{array}$ & 98 & 2 & 2 & * & 1102 & 4.0 & 4 & & 3.8 & 4 \\
\hline $\begin{array}{l}\text { i. } A b \\
\text { Q8 }\end{array}$ & 2 & 1.57 & 1 & .0 & 51 & 3.26 & 4 & * & 2.70 & 3 \\
\hline Abl & 9 & 2.34 & 2 & & 1,097 & 4.02 & 4 & & 3.77 & 4 \\
\hline & 73 & 1.73 & 1 & $.000 * *$ & 1,067 & 3.47 & 4 & .0 & 3.22 & 4 \\
\hline $\begin{array}{r}\text { 1. } \mathrm{Ab} \\
\mathrm{O}\end{array}$ & 5 & 1 & 1 & $.000 * *$ & 1,074 & 3 & 4 & * & 2 & 3 \\
\hline m. Al & & & 1 & & & 2 & 3 & & 2.20 & 1 \\
\hline n. $\mathrm{Ab}$ & 1,084 & 1.54 & 1 & $.000 * *$ & 1,084 & 3.29 & 3 & $.000 * *$ & 2.63 & 3 \\
\hline $\begin{array}{l}\text { o. Ab } \\
\text { usil }\end{array}$ & + & 2. & 2 & $.000 * *$ & 5 & 3 & 4 & 5* & 3.69 & 4 \\
\hline p. Ab & 1,112 & 2 & 3 & * & 10 & 4 & 4 & 458 & 4.06 & 4 \\
\hline $\begin{array}{l}\text { q. Able } \\
\text { mov }\end{array}$ & 109 & 2.62 & 3 & $.000^{* *}$ & 1,113 & 3.75 & 4 & 267 & 3.72 & 4 \\
\hline $\begin{array}{l}\text { r. Able } \\
\text { Pon }\end{array}$ & & 1.44 & 1 & .00 & $18+2-3$ & 3.41 & 4 & & 2.58 & 2 \\
\hline
\end{tabular}

M: average; Me: median; $N^{1}$ : number of respondents for comparison of pretest and survey; $P^{1}: P$-value for comparison of pretest and survey; $N^{2}$ : number of respondents for comparison of posttest and survey; $P^{2}: P$-value for comparison of posttest and survey; **: significant at $P<.001$; *: significant at $P<.005$

The level of retention of ICT skills acquired through the DL training course (as perceived by the students) differed depending on the age of students. Students' everyday use of a PC and the Internet is associated with the level of retention of perceived ICT skills acquired through the DL training course. Students' learning methods are associated with the level of retention of perceived ICT skills acquired through the DL training course.

\section{METHODOLOGY}

We sent a survey questionnaire on November 10, 2013 to 2,112 OUJ students who had taken a DL training course between the second semester of 2010 and the first semester of 2013 and had OUJ student status in September 2013. In other words, students were sampled at some point between one and three years after completion of the DL training course. The questionnaire included questions on the following: the frequency and purpose of PC and 
Internet usage; opportunities to learn DL skills after the training course; the same 18 ICT skills (Table 1) measuring the learning outcomes that were included in the checklist to be evaluated on a 5-point Likert scale; and five questions to measure perceived self-efficacy on a 4-point Likert scale. Recipients were requested to provide handwritten responses using surface mail or submit responses via a dedicated website. We received 1,153 responses (1,038 by surface mail and 115 online; response rate, 54\%) by March 31, 2014. With the removal of 20 responses in which most of the items were left blank, 1,133 effective responses were used for data analysis. We combined each respondent's survey response with checklist data using student ID. We also analyzed the relationship between age and ICT skills, PC/Internet usage, and changes in ICT skills, as well as post-course continuing learning and changes in ICT skills.

\section{RESULTS}

\section{General Changes in Perceived DL Skills}

Eighteen items in the checklist measured students' ICT skills as reflected in their learning outcomes. Although the Likert scale data are rank ordered, for convenience we calculated the mean and median values for these 18 items on the pretest, posttest, and survey questionnaires. Table 1 presents the general changes in students' perceived ICT skills. Skill levels tended to increase significantly from pretest to posttest. A statistical analysis using the Wilcoxon signed-rank test for correlated samples $(P<.05)$ was conducted to compare pretest and posttest scores. The result indicates that students' perceived DL skills were significantly improved on all 18 measures. We also compared posttest and survey data, and found that scores for all ICT skills declined, except for "Able to input Japanese letters using a keyboard" and "Able to copy, save, delete, and move files.” These two skills (typing and file management) are required for almost all types of PC use, and they likely improved through everyday use of a PC. In contrast, any decline in perceived skill level may be attributed to relatively infrequent usage.

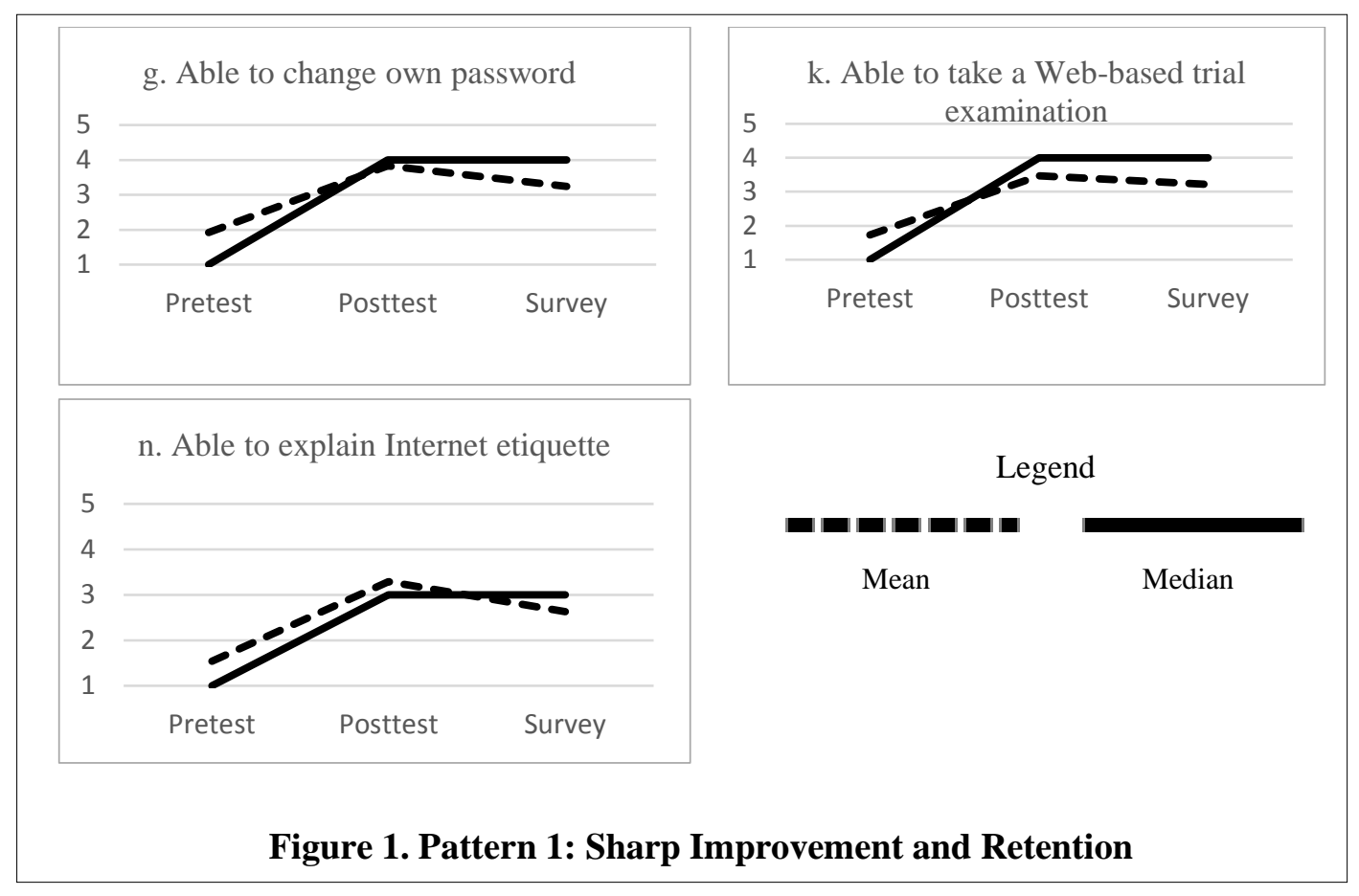




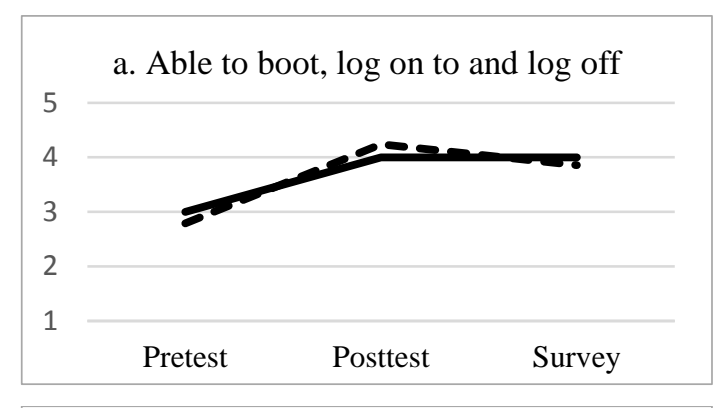

d. Able to access the OUJ webpage
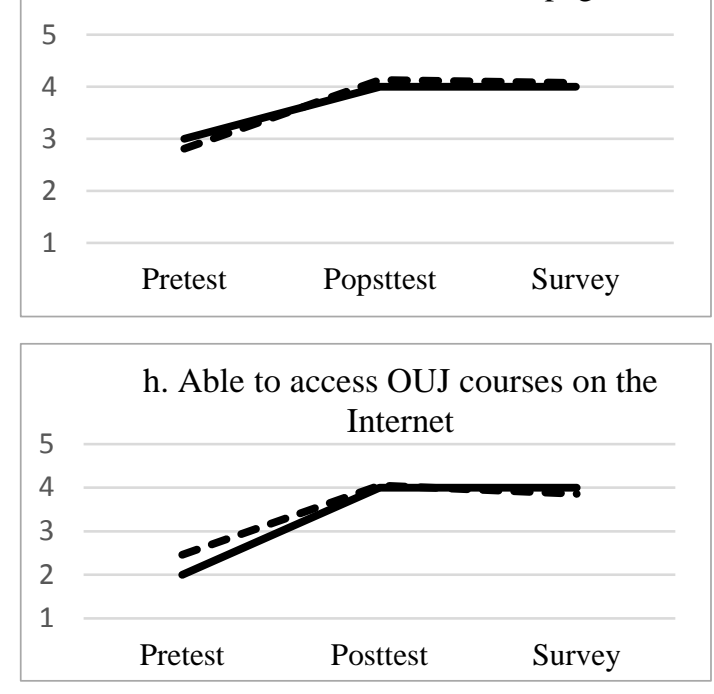

o. Able to compose a simple essay

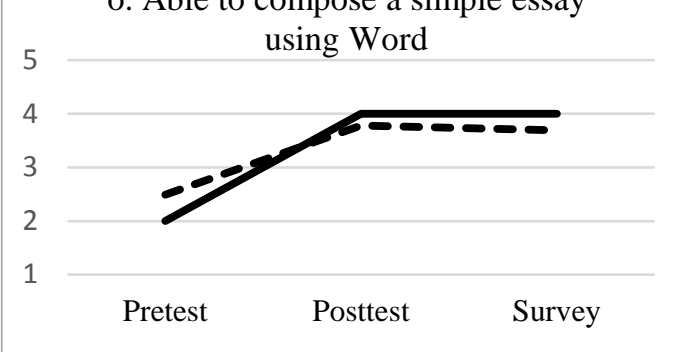

Legend

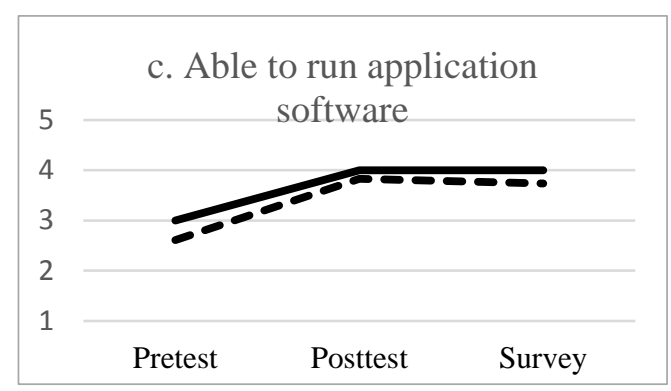

e. Able to search for information using a search engine
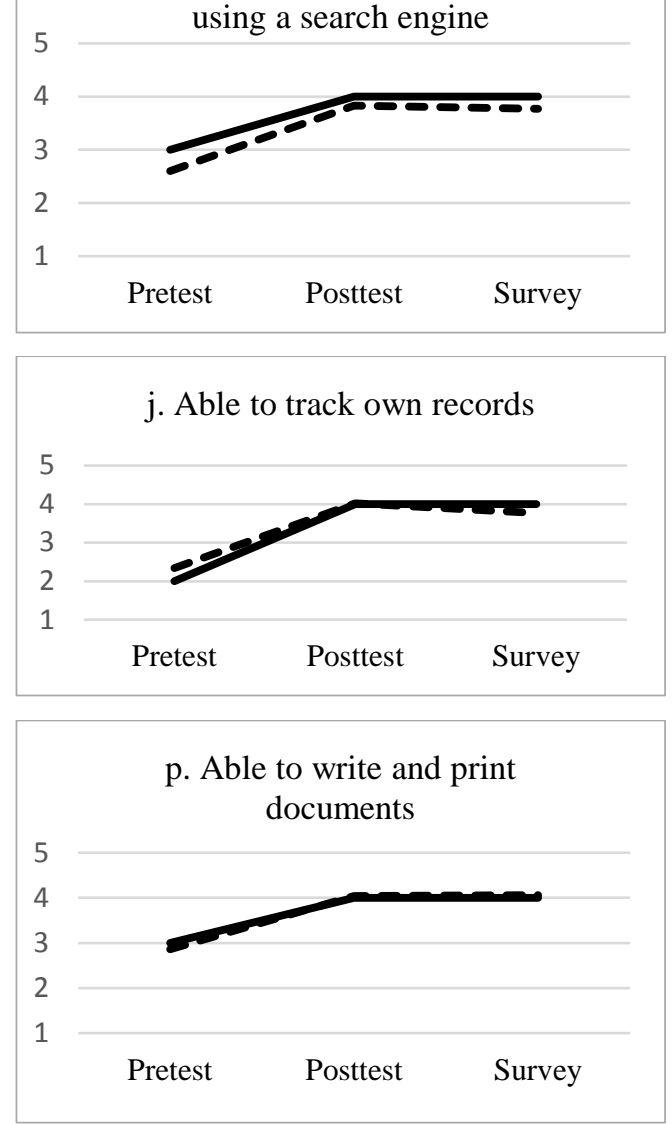

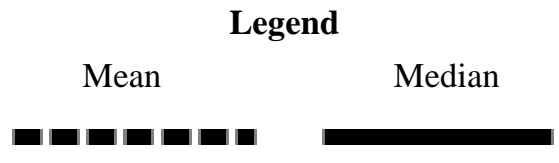

Figure 2. Pattern 2: Moderate Improvement and Retention

\section{Pattern of Changes in ICT Skills}

Changes in the mean and the median scores for each ICT skill measure revealed four patterns:

- Pattern 1. A median score of 1 (“cannot do/never done”) for pretest, a sharp improvement for posttest, and retaining the level in the Survey. Three items of ICT skills "g. Able to change own password," "k. Able to take a Web-based trial examination," and "n. Able to explain Internet etiquette" (Figure 1) exhibited this pattern. Most of the students learned these three ICT skills for the first time during the DL training course through practice. It is likely that they subsequently retained these skills because many students used them 
after completion of the course.

- Pattern 2. A moderate median score of 2 ("it was done") or 3 ("might be able to do") for the pretest, improving to a higher level (4: can do) for the posttest, and retaining the level for the survey. Nine items including "a. Able to boot, log on to and log off," "c. Able to run application software," "d. Able to access the OUJ webpage," "e. Able to search for information using a search engine," "h. Able to access OUJ courses on the Internet," "j. Able to track own records," "o. Able to compose a simple essay using Word," "p. Able to write and print documents," and "q. Able to copy, save, delete, and move files” are categorized as conforming to Pattern 2 (see Figure 2). A majority of students had some prior practical experience of these ICT skills. The skill level was improved during the DL training course through practice. Students retained these skills probably because they practiced them in everyday PC and Internet use after taking the DL training course.

- Pattern 3. A low median score of 1 ("cannot do/never done") for the pretest, improving to a higher level for the posttest, but declined by the time of the survey. Five ICT skills were classified under this category: "f. Able to exchange emails using an OUJ account," "i. Able to send questions to the OUJ Q\&A site," "l. Able to check out books using the OUJ OPAC," "m. Able to remove a computer virus," and "r. Able to create 5-6 slides using PowerPoint” (see Figure 3).
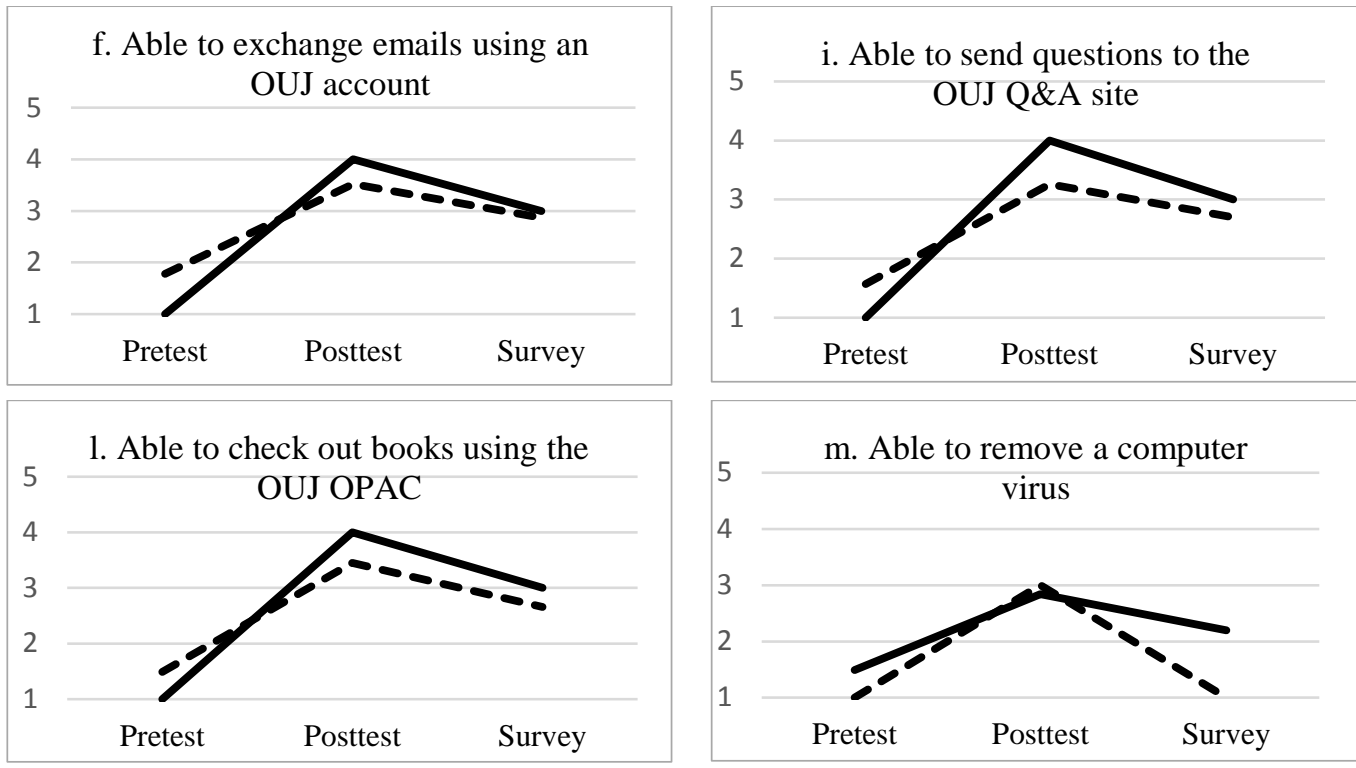

l. Able to check out books using the
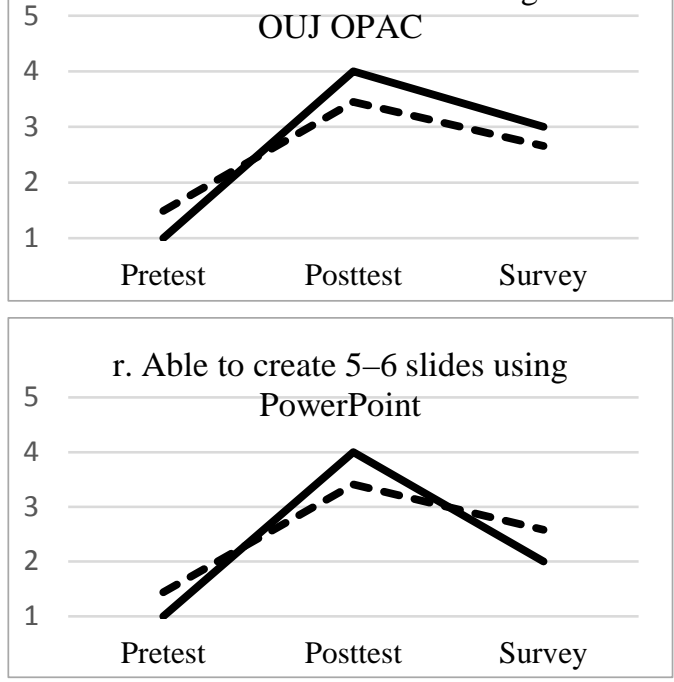

Legend

Mean

Median

Figure 3. Pattern 3: Abrupt Improvement and Decline 

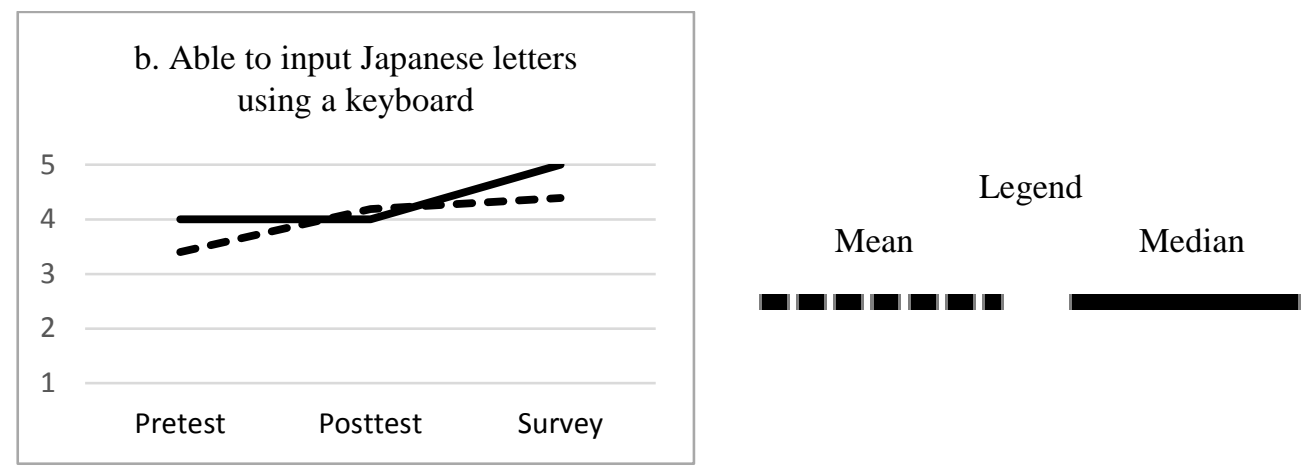

Figure 4. Pattern 4: Moderate Improvement

Table 2. Changes in Perceived Self-Efficacy

\begin{tabular}{|c|c|c|c|c|c|c|c|c|c|}
\hline \multirow{2}{*}{ ICT Skill (Learning Outcome) } & \multirow{2}{*}{$\mathrm{N}^{1}$} & \multicolumn{2}{|c|}{ Pretest } & \multirow{2}{*}{$P^{1}$} & \multirow{2}{*}{$\mathrm{N}^{2}$} & \multicolumn{2}{|c|}{ Posttest } & \multirow{2}{*}{$P^{2}$} & Survey \\
\hline & & $M$ & Me & & & $M$ & $M e$ & & $M \quad M e$ \\
\hline s. Using a PC is enjoyable & 1,082 & 2.98 & 3 & $.000^{* *}$ & 1,094 & 3.414 & & $.000^{* *}$ & 3.093 \\
\hline $\begin{array}{l}\text { t. The PC is useful for studying at } \\
\text { OUJ }\end{array}$ & 1,114 & 3.55 & 4 & $.001^{* *}$ & 1,106 & 3.794 & & $.000^{* *}$ & 3.624 \\
\hline u. I feel anxious about using a PC & 1,067 & 2.62 & 3 & $.000 * *$ & 1,105 & 2.483 & & .051 & 2.422 \\
\hline v. A PC is useful in everyday life & 1,098 & 3.61 & 4 & .358 & 1,107 & 3.724 & & $.000^{* *}$ & 3.594 \\
\hline $\begin{array}{l}\text { w. I would actively use a PC from } \\
\text { now on }\end{array}$ & 1,071 & 3.62 & 4 & $.000 * *$ & 1,111 & 3.714 & & $.000^{* *}$ & 3.504 \\
\hline
\end{tabular}
value for comparison of pretest and survey; $N^{2}$ : number of respondents for comparison of posttest and survey; $P^{2}$ : $P$-value for comparison of posttest and survey; **: significant at $P<.001$; *: significant at $P>.005$

Most of the students did not have experience in performing these tasks before they attended the DL training course. Although they learned these skills through practice, they likely declined because students seldom used them after they completed the course.

- Pattern 4. A moderate median score of 2 ("it was done") or 3 ("might be able to do") for the pretest, improving to a higher level (4: can do) for the posttest, and progressing to the highest level (5: can do with confidence) for the survey (see Figure 4). Only one ICT skill ("b. Able to input Japanese letters using a keyboard") fell into this category. We assume that most of the students had experience with this skill before attending the DL training course. They practiced touch typing during the DL training course and kept using this skill in everyday PC and the Internet usage, so their perceived skill level improved.

\section{General Changes in Perceived Self-Efficacy}

Five items in the checklist (s- $\mathrm{w}$ in Table 2 ) and the survey measured students' perceived selfefficacy on a 4-point Likert scale (1: completely disagree; 2: somewhat disagree; 3: somewhat agree; 4: completely agree). We calculated the mean and median values for these five items on the pretest, posttest, and survey questionnaires. A statistical analysis using the Wilcoxon signed-rank test for correlated samples was conducted to compare pretest and posttest scores. Except for the item “Using a PC is enjoyable," students' perceived self-efficacy improved in 


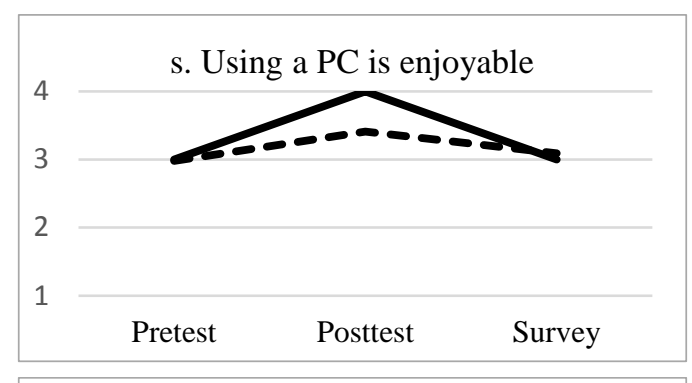

u. I feel anxious about using PC

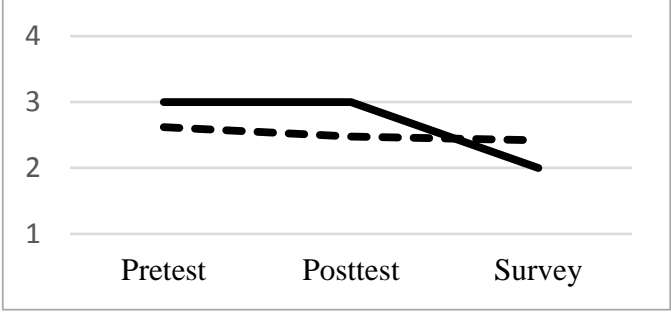

w. I would actively use a PC from now on

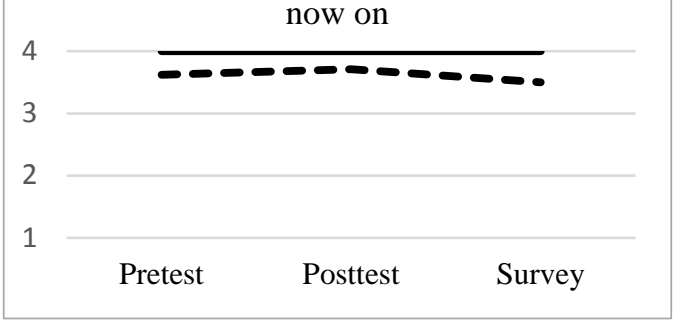

t. The PC is useful for studying at OUJ

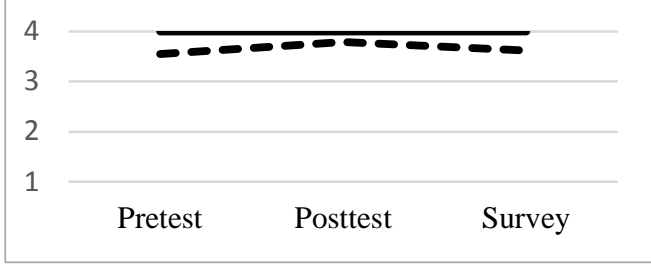

v. A PC is useful in everyday life

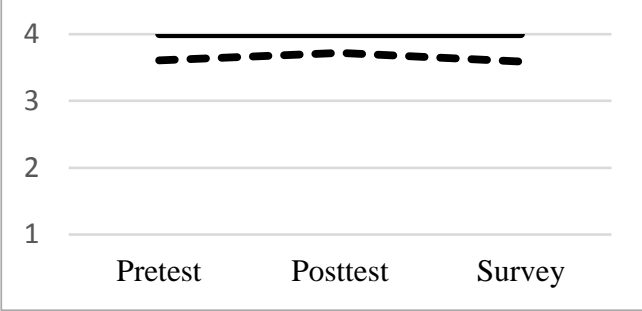

Legend

Mean

Median

\section{Figure 5. Changes in Perceived Self-Efficacy}

the survey compared with the pretest. Comparison between the posttest and the survey indicates that, except for "I feel anxious using PC" (reverse-scored item), all four items showed a significant difference. Table 2 presents the general changes in students' perceived self-efficacy.

\section{Pattern of Changes in Perceived Self-Efficacy}

Changes in the mean and the median scores for each item of perceived self-efficacy are presented in Figure 5. The median values of three items of perceived self-efficacy ("t. The PC is useful for studying at OUJ," "v. A PC is useful in everyday life," and "w. I would actively use a PC from now on") were highest even before students attended the course, and these values remained unchanged in the survey. The median of "s. Using a PC is enjoyable" was relatively high for the pretest, improved for the posttest, but declined by the time of the survey. In contrast, the median of "u. I feel anxious about using a PC" (a reverse-scored item) was relatively high for the pretest and posttest, but was lower (i.e., anxiety was lower) for the survey. Thus, the anxiety level of students improved one to three years after they attended the course. 
Table 3. Difference in Retention of ICT Skills by Age

\begin{tabular}{|c|c|c|c|c|c|c|c|c|}
\hline \multirow{2}{*}{ ICT Skill } & \multicolumn{3}{|c|}{$\geq 61$ years } & \multicolumn{3}{|c|}{$\leq 60$ years } & \multirow{2}{*}{$\begin{array}{c}\text { Mann- } \\
\text { Whitney } U\end{array}$} & \multirow{2}{*}{$\boldsymbol{P}$} \\
\hline & $\mathrm{N}$ & $M$ & $M e$ & $N$ & $M$ & $\mathrm{Me}$ & & \\
\hline a. Able to boot, log on to and log off & 614 & -.39 & 0 & 468 & -.34 & 0 & $140,227.5$ & .467 \\
\hline b. Able to input Japanese letters using a keyboard & 638 & .26 & 0 & 476 & .12 & 0 & 165,574 & $.004 *$ \\
\hline c. Able to run application software & 602 & -.06 & 0 & 465 & -.11 & 0 & $143,662.5$ & .433 \\
\hline d. Able to access the OUJ webpage & 619 & -.05 & 0 & 479 & -.08 & 0 & $150,424.5$ & .647 \\
\hline $\begin{array}{l}\text { e. Able to search for information using a search } \\
\text { engine }\end{array}$ & 603 & -.12 & 0 & 468 & -.04 & 0 & 136,157 & .287 \\
\hline f. Able to exchange emails using an OUJ account & 609 & -.71 & 0 & 468 & -.60 & 0 & 135,212 & .134 \\
\hline g. Able to change own password & 620 & -.64 & 0 & 473 & -.52 & 0 & 139,929 & .175 \\
\hline h. Able to access OUJ courses on the Internet & 627 & -.22 & 0 & 475 & -.17 & 0 & $146,795.5$ & .661 \\
\hline i. Able to send questions to the OUJ Q\&A site & 588 & -.64 & 0 & 463 & -.45 & 0 & 125,985 & $.029 *$ \\
\hline j. Able to track own records & 624 & -.27 & 0 & 473 & -.24 & 0 & $144,095.5$ & .469 \\
\hline k. Able to take a Web-based trial examination & 599 & -.32 & 0 & 468 & -.18 & 0 & 131,296 & .063 \\
\hline 1. Able to check out books using the OUJ OPAC & 602 & -.87 & -1 & 472 & -.71 & 0 & 131,640 & $.032 *$ \\
\hline m. Able to remove a computer virus & 610 & -.64 & 0 & 472 & -.64 & 0 & 144,097 & .978 \\
\hline n. Able to explain Internet etiquette & 615 & -.73 & -1 & 469 & -.59 & 0 & $133,894.5$ & $.036^{*}$ \\
\hline o. Able to compose a simple essay using Word & 629 & -.05 & 0 & 476 & -.14 & 0 & 156,013 & .203 \\
\hline p. Able to write and print documents & 636 & .09 & 0 & 474 & -.05 & 0 & $161,056.5$ & $.032 *$ \\
\hline q. Able to copy, save, delete, and move files & 639 & .00 & 0 & 474 & -.07 & 0 & $155,584.5$ & .302 \\
\hline r. Able to create 5-6 slides using PowerPoint & 613 & -.90 & -1 & 473 & -.71 & -1 & $130,869.5$ & $.005^{* *}$ \\
\hline
\end{tabular}

M: average; Me: median; $P^{1}$ : P-value for comparison of the posttest and the survey; $* *$ : significant at $P<.001$; *: significant at $P>.005$

\section{Age and Retention of ICT Skills}

Survey respondents were divided into two age groups ( $\leq 60$ and $\geq 61$ years) at the time they attended the DL training course. Changes in 18 ICT skills between the posttest and the survey were analyzed using the Mann-Whitney $U$ test $(\alpha=.05)$ (Table 3).

Five items of perceived level of ICT skills were significantly different. The older age group improved in "b. Able to input Japanese letters using a keyboard.” This is perhaps because older students had less experience in using a keyboard before they attended the DL training course. In contrast, a decline was observed for four items including "i. Able to send questions to the OUJ Q\&A site”, "l. Able to check out books using the OUJ OPAC”, "r. Able to create 5-6 slides using PowerPoint". As there was no hands-on training for the skills "Able to send questions to the OUJ Q\&A site” or “Able to explain Internet etiquette,” older students might have forgotten these ICT skills by the time of the survey.

Similar analysis was conducted for perceived self-efficacy (Table 4). The results show that two items of perceived self-efficacy were significant. The anxiety level of older students improved, while the perceived usefulness of the PC declined for the younger age group. 
Table 4. Difference in Changes of Perceived Self-Efficacy by Age

\begin{tabular}{|c|c|c|c|c|c|c|c|c|}
\hline \multirow{2}{*}{ Perceived Self-Efficacy } & \multicolumn{3}{|c|}{$\geq 61$ years } & \multicolumn{3}{|c|}{$\leq 60$ years } & \multirow{2}{*}{$\begin{array}{c}\text { Mann- } \\
\text { Whitney } \\
U\end{array}$} & \multirow[t]{2}{*}{$\boldsymbol{P}$} \\
\hline & $\mathrm{N}$ & $M$ & $M e$ & $N$ & $M$ & $M e$ & & \\
\hline s. Using a PC is enjoyable & 524 & -.34 & 0 & 470 & -.30 & 0 & $143,717.5$ & .530 \\
\hline t. The PC is useful for studying at OUJ & 633 & -.17 & 0 & 473 & -.17 & 0 & $148,939.5$ & .857 \\
\hline u. I feel anxious about using a PC & 632 & -.15 & 0 & 473 & .06 & 0 & $132,680.5$ & $.001^{* *}$ \\
\hline v. A PC is useful in everyday life & 634 & -.09 & 0 & 473 & -.19 & 0 & $158,684.5$ & $.038 *$ \\
\hline w. I would actively use a PC from now on & 637 & -.22 & 0 & 474 & -.21 & 0 & $148,500.5$ & .584 \\
\hline
\end{tabular}

Table 5. Perceived Skill and Frequency of PC Use

\begin{tabular}{lcccrc}
\hline Frequency of PC Use & Retain & Decline & Total & $\chi^{2}$ & $\boldsymbol{P}$ \\
\hline 6 days/week & $194(48.4 \%)$ & $207(51.6 \%)$ & $401(100 \%)$ & 55.59 & $.000^{* *}$ \\
4-5 days/week & $61(32.1 \%)$ & $129(67.9 \%)$ & $190(100 \%)$ & .44 & .507 \\
2-3 days/week & $53(29.3 \%)$ & $128(70.7 \%)$ & $181(100 \%)$ & 2.14 & .144 \\
1 day/week & $38(27.0 \%)$ & $103(73.0 \%)$ & $141(100 \%)$ & 3.98 & $.046^{*}$ \\
1 day/2-3 weeks & $11(17.7 \%)$ & $51(82.3 \%)$ & $62(100 \%)$ & 8.30 & $.004^{* *}$ \\
Less than 1 day/month & $13(20.3 \%)$ & $51(79.7 \%)$ & $64(100 \%)$ & 5.80 & $.016^{* *}$ \\
No use & $15(18.1 \%)$ & $68(81.9 \%)$ & $83(100 \%)$ & 10.34 & $.001^{* *}$ \\
Total & $385(34.3 \%)$ & $737(65.7 \%)$ & $1122(100 \%)$ & & \\
\hline \multicolumn{7}{l}{ (3) significant at $P<.001 ; *$ significant at $P>.005$} & &
\end{tabular}

Table 6. Perceived Skill and Frequency of Internet Use

\begin{tabular}{|c|c|c|c|c|c|}
\hline $\begin{array}{c}\text { Frequency of Internet } \\
\text { Use }\end{array}$ & Retain & Decline & Total & $\chi^{2}$ & $\boldsymbol{P}$ \\
\hline 6 days/week & $182(47.5 \%)$ & $201(52.5 \%)$ & $383(100 \%)$ & 46.86 & $.000^{* *}$ \\
\hline 4-5 days/week & 67 (35.3\%) & $123(64.7 \%)$ & $190(100 \%)$ & .081 & .776 \\
\hline 2-3 days/week & $63(35.0 \%)$ & 117 (65.0\%) & $180(100 \%)$ & .063 & .802 \\
\hline 1 day/week & 31 (25.4\%) & $91(76.4 \%)$ & 122 (100\%) & 5.68 & $.30 *$ \\
\hline 1 day/2-3 weeks & $8(15.4 \%)$ & $44(84.6 \%)$ & $52(100 \%)$ & 8.56 & $.003^{* *}$ \\
\hline Less than 1 day/month & $11(15.9 \%)$ & 58 (84.1\%) & 69 (100\%) & 10.87 & $.001^{* *}$ \\
\hline No use & $22(18.2 \%)$ & $99(81.8 \%)$ & $121(100 \%)$ & 15.43 & $.000 * *$ \\
\hline Total & 385 (34.3\%) & 737 (65.7\%) & $1122(100 \%)$ & & \\
\hline
\end{tabular}

\section{Relationship between Perceived ICT Skills and PC Usage}

After the DL training course, respondents used a PC for a variety of purposes including word processing, creating spreadsheets and graphs, giving presentations, and managing visual images. Table 5 compares the average scores on all items for each participant's perceived ICT skill identified in posttest and survey results with frequency of PC use (survey item). We divided respondents into two groups: Retain is a group of students whose average survey score on all items was equal or higher than that in the posttest; Decline is a group of students whose average score was lower than that of the posttest. We compared these two groups in 
Table 7. Learning Practices and Perceived Skills

\begin{tabular}{|c|c|c|c|c|c|}
\hline Learning Method & Retain & Decline & Total & $\chi^{2}$ & $P$ \\
\hline Self-instruction & $221(40.0 \%)$ & $332(60.0 \%)$ & $553(100 \%)$ & 16.03 & $.000^{* *}$ \\
\hline $\begin{array}{l}\text { Learning from a family } \\
\text { member }\end{array}$ & 81 (32.4\%) & $169(67.6 \%)$ & $250(100 \%)$ & .45 & .500 \\
\hline Learning from a friend & 53 (35.3\%) & 97 (64.7\%) & $150(100 \%)$ & .10 & .751 \\
\hline $\begin{array}{l}\text { Joining a learning } \\
\text { community }\end{array}$ & 31 (51.7\%) & 29 (48.3\%) & 60 (100\%) & 8.60 & $.003^{* *}$ \\
\hline Taking a TV course & $53(47.7 \%)$ & 58 (52.3\%) & 332 (60.0\%) & 10.06 & $.002 * *$ \\
\hline Total & 387 (34.2\%) & 745 (65.8\%) & $1,132(100 \%)$ & & \\
\hline
\end{tabular}

terms of PC use. Results in Table 5 clearly indicate that students in the Retain group used PCs significantly more frequently than those in the Decline group.

\section{Relationship between Perceived Skills and Internet Usage}

Respondents used the Internet for a variety of purposes, including information retrieval, email, taking OUJ courses, using OUJ's remedial learning site, registering for courses, taking midterm examinations, accessing the library, and shopping and social networking services (SNS). Table 6 compares overall average scores for perceived DL skill levels identified in posttest and survey results with frequency and purpose of Internet use (single item). Again, we divided respondents into the two groups Retain and Decline. We compared these two groups in terms of Internet use. Result in Table 6 clearly indicate that students in the Retain group used the Internet significantly more frequently than those in the Decline group.

\section{Relationship between Perceived Skills and Continuing Learning}

We assume that students who continue to learn DL skills after the course are likely to retain or improve their skills. A chi-squared test was conducted to compare the two groups Retain and Decline (DF = 2) (Table 7). The analysis indicates that "Self-instruction," "Joining a learning community," and "Taking a TV course" are significant, but "Learning from a family member," and "Learning from a friend" are not significant $(P<.001)$. Thus, the former three practices contributed to retaining DL skills, while the latter two did not.

These results are useful for planning post course support for DL students. We recommend that students take TV distance-learning courses to help retain the DL skills they acquired in the course. Because many study centers have their own PC circles, we encourage students to join one to have the opportunity for peer learning. If there is no existing learning community at the study center, it would be desirable to create one.

\section{DISCUSSION}

The summary results related to the four research hypotheses are as follows:

1. The results indicate that the perceived level of ICT skills categorized as Patterns 1 and 2 was retained, while Pattern 4 improved. In contrast, Pattern 3 declined. 
2. Retention of the perceived level of ICT skills differed between students in the two age groups, as did the perception of self-efficacy.

3. Retention of the perceived level of ICT skills was positively related to the frequency of PC and Internet usage by students.

4. Self-instruction, joining a learning community, and taking TV courses had a significant effect in the retention of the perceived level of ICT skills.

The four patterns of changes in students' perceived ICT skills in the pretest, posttest, and survey questionnaire suggest that the declining ICT skills categorized as Pattern 3 (e-mail exchange, sending questions, check out books of library, remove computer vires, and create PowerPoint slides) are problematic. We need to reinforce these skills by introducing a more effective way of teaching, by encouraging students to continue using the PC/Internet and taking TV distance-learning courses, and by establishing a PC learning community at each study center.

By visualizing and comparing how the perceived level of each ICT skill changed across the pretest, posttest, and survey questionnaires, we could readily recognize the ICT skills that students retained or not. It is quite reasonable to expect that a posttest score would be higher than the pretest score if measured on completion of the DL course. However, it is more important to demonstrate which skills are retained long after the training course is over. The method of analysis implemented in this study - in particular, the technique we used to visualize the changes in perceived ICT skills in the pretest, posttest, and survey questionnaires - has proved useful in identifying problematic skills, with the purpose of seeking more effective ways of teaching and planning post course support for students.

\section{CONCLUSION}

The Open University of Japan (OUJ) has offered a digital literacy (DL) training course every semester at its 50 study centers since 2010. Students' DL skills, measured using a selfadministered survey of their learning outcomes, indicated that their skills were significantly improved by taking the course. We found that on average, students' typing and filemaintenance skills (i.e., everyday PC practices) were retained or even improved, while other skills declined. Students who used a PC and the Internet more frequently retained the DL skills learned in the course. In addition, self-instruction, peer learning in the community, and televised distance-learning courses were seen as helping students retain their DL skills.

These findings are useful, not only for improving future DL training courses, but also for suggesting ways to help students retain their DL skills. Based on the study findings, we recommend that students take OUJ's televised "PC for Distance Learning" course and join a PC circle for continuing learning to retain the DL literacy skills learned in the DL training course.

\section{ACKNOWLEDGMENTS}

We are grateful to all the lecturers who have taught DL training courses and who conducted the self-administered checklist, and to students who attended the courses and responded to the survey. This research project has been partially supported by a research grant provided by the Foundation for the Promotion of the Open University of Japan. 


\section{REFERENCES}

Czaja, S. J., Charness, N., Fisk, A. D., Hertzog, C., Nair, S. N., Rogers, W. A., \& Sharit, J. (2006). Factors predicting the use of technology: findings from the Center for Research and Education on Aging and Technology Enhancement (CREATE). Psychology and Aging, 21(2), 333-352.

Echt, K. V., Morrell, R. W., \& Park, D. C. (1998). Effects of age and training formats on basic computer skill acquisition in older adults. Educational Gerontology: An International Quarterly, 24(1), 3-25.

Miwa, M., Takahashi, H., Nishina, E., Hirose, Y., Yaginuma, Y., Kawafuchi, A., \& Akimitsu, T. (2013, October). Digital library training for elderly students at the Open University of Japan. In Kurbanoğlu, S., Grassian, E., Mizrachi, D., Catts, R., \& Špiranec, S. (Eds.), European Conference on Information Literacy (pp. 205-211). Switzerland: Springer International Publishing.

Naumanen, M., \& Tukiainen, M. (2010). Practices in old age ICT education. In Spector J., Ifenthaler D., Isaias P., Kinshuk, Sampson D. (Eds.), Learning and Instruction in the Digital Age (p. 283). Boston: Springer.

OECD (2005). Learning a living: First results of the Adult Literacy and Life Skills survey. Retrieved from http://www.oecd.org/education/innovation-education/34867438.pdf

Schäffer, B. (2007). The digital literacy of seniors. Research in Comparative and International Education, 2(1), 29-42.

Wong, Y. C., Chen, H., Lee, V. W., Fung, J. Y., \& Law, C. K. (2014). Empowerment of senior citizens via the learning of information and communication technology. Ageing International, 39(2), 144-162. 